\title{
Efeitos da aplicação de manganês no crescimento, na nutrição e na produção de matéria seca de plantas de Brachiaria brizantha (cv. MG4) em condições de casa de vegetação
}

\author{
Aline Peregrina Puga ; Renato de Mello Prado ${ }^{2}$; Danilo Mesquita Melo ; Isabella Mazer Guidi ; Kamilla Ortega \\ Saulo Strazeio Cardoso ${ }^{6}$; Thiago Batista Almeida ${ }^{7}$
}

\section{RESUMO}

A adubação com micronutrientes, como o manganês em gramíneas forrageiras tropicais, contribui para o atendimento das exigências nutricionais tanto das plantas quanto dos animais. Objetivou-se, neste trabalho, estudar os efeitos da aplicação de manganês no crescimento, na nutrição e na produção de matéria seca de plantas de Brachiaria brizantha, em condições de casa de vegetação. Para isto, realizou-se um experimento em casa de vegetação da FCAV/

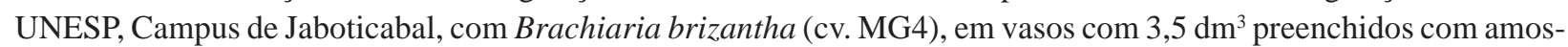
tras de um Latossolo Vermelho distrófico $\left(\mathrm{Mn}=0,6 \mathrm{mg} \mathrm{dm}^{-3}\right)$. O delineamento experimental foi inteiramente casualizado, com cinco tratamentos, que corresponderam às doses de manganês $\left(0,15,30,60\right.$ e $\left.120 \mathrm{mg} \mathrm{dm}^{-3}\right)$, e quatro repetições. Avaliaram-se, nos dois cortes da forrageira (primeiro corte, 35 dias após o transplantio e, segundo, 30 dias após o primeiro), as variáveis de crescimento, produção de massa de forragem, teor e acúmulo de Mn na parte aérea. As doses de manganês aplicadas aumentaram a concentração deste micronutriente no solo e nas plantas e a produção de massa de forragem no primeiro corte. A Brachiaria brizantha cv. MG4 apresenta alta tolerância ao manganês, atingindo elevados teores de Mn na parte aérea, mesmo sem provocar sintomas visuais de toxicidade.

Palavras-chave: Brachiaria brizantha, nutrição mineral, desordem nutricional, micronutriente, Mn.

\section{ABSTRACT}

\section{Effects of manganese on growth, nutrition and dry matter production of plants of Brachiaria brizantha (cv. MG4) in greenhouse conditions}

A fertilizer with micronutrients, such as manganese in tropical forage grasses, helps to meet the nutritional requirements of both, plants and animals. The objective of this work was to study the effects of applying manganese in growth, nutrition and dry matter production of plants of Brachiaria brizantha (Hochst. ex A Rich.) Stapf in greenhouse conditions. For this, an experiment was conducted in the FCAV/UNESP, Jaboticabal, Brazil. Brachiaria brizantha plants were cultivated in pots containing $3,5 \mathrm{dm}^{3}$ filled with samples of an Oxisol $\left(\mathrm{Mn}: 0,6 \mathrm{mg} \mathrm{dm}^{-3}\right)$. The experimental

Recebido para publicação em 31/03/2011 e aprovado em 03/11/2011

'Engenheira Agrônoma, Mestre. Centro de Solos e Recursos Agroambientais, Instituto Agronômico de Campinas (IAC), Avenida Barão de Itapura, nº1481, 13012-970, Campinas, SP, Brasil. linepuga@yahoo.com.br

${ }^{2}$ Engenheiro Agrônomo, Doutor. Departamento de Solos e Adubos, UNESP/FCAV, Via de acesso Prof. Paulo Donato Castellane, s/n, 14884-900, Jaboticabal, São Paulo, Brasil. rmprado@fcav.unesp.br

${ }^{3}$ Engenheiro Agrônomo, Mestre. Departamento de Produção Vegetal, UNESP/FCAV, Via de acesso Prof. Paulo Donato Castellane, s/n, 14884-900, Jaboticabal, São Paulo, Brasil. melo.agro@hotmail.com

${ }^{4}$ Engenheira Ambiental. Departamento de Solos e Adubos, UNESP/FCAV, Via de acesso Prof. Paulo Donato Castellane, s/n, 14884-900, Jaboticabal, São Paulo, Brasil. isabella_guidi@yahoo.com.br

${ }^{5}$ Engenheira Agrônoma, Mestre. Departamento de Tecnologia, UNESP/FCAV, Via de acesso Prof. Paulo Donato Castellane, s/n, 14884-900, Jaboticabal, São Paulo, Brasil. millaortega@yahoo.com.br

${ }^{6}$ Engenheiro Agrônomo. Departamento de Solos e Adubos, UNESP/FCAV, Via de acesso Prof. Paulo Donato Castellane, s/n, 14884-900, Jaboticabal, São Paulo, Brasil. strazeio@yahoo.com.br

${ }^{7}$ Engenheiro Agrônomo, Mestre. Departamento de Solos e Adubos, UNESP/FCAV, Via de acesso Prof. Paulo Donato Castellane, s/n, 14884-900, Jaboticabal, São Paulo, Brasil. thibalmeida@gmail.com 
design was completely randomized design with five treatments that corresponded to doses of manganese $(0,15,30,60$ and $120 \mathrm{mg} \mathrm{dm}^{-3}$ ) and four replications. We evaluated the variables of growth, forage mass production, content and accumulation of $\mathrm{Mn}$ in the shoot in two cuts of the forage, the first, 35 days after transplanting and the second, 30 days after the first. The applied doses of manganese increased the concentration of this micronutrient in soil and plants, and the mass production of fodder in the first cut. The Brachiaria brizantha cv. MG4 has a high tolerance to manganese reaching high levels of $\mathrm{Mn}$ in the shoot without causing visual symptoms of toxicity.

Key words: Brachiaria brizantha (Hochst. ex A. Rich.) Stapf, mineral nutrition, nutritional disorder, micronutrients, $\mathrm{Mn}$.

\section{INTRODUÇÃO}

Uma das opções para a formação de pastos, no Brasil, são as gramíneas do gênero Brachiaria, que têm-se firmado pela capacidade de adaptação às diversas condições ambientais e de manejo (Monteiro et al., 1995). São excelentes forrageiras perenes e com grande produção de massa foliar de boa qualidade (Kissman, 1997), sendo importantes fontes de nutrientes para os animais em pastejo (Soder \& Stout, 2003).

Contudo, Braz et al. (2002) afirmaram que o tipo de solo e a baixa fertilidade afetam a qualidade nutritiva das forrageiras, limitando o consumo de nutrientes dos animais e não atendendo às suas exigências. Nesse sentido, a adubação e a calagem do solo cultivado com gramíneas são práticas importantes, que contribuem para o atendimento das exigências nutricionais dos animais. A deficiência e o excesso de nutrientes nos pastos tropicais são responsáveis pela baixa produção e por problemas reprodutivos em animais (Mcdowell \& Valle, 2000).

Os pastos cultivados ocupam grande parte do território brasileiro; porém, até recentemente, não eram considerados culturas e não recebiam os devidos cuidados com relação aos teores de nutrientes (Oliveira et al., 2007). A vasta utilização de solos com teores de nutrientes naturalmente baixos e o esgotamento de solos férteis (Pereira et al., 2001), além da aplicação de altas doses de calcário, têm contribuído para aumentar a deficiência de manganês nas plantas cultivadas (Tanaka et al., 1993; Sanzonowicz, 1995).

O manganês é importante para o crescimento vegetal, pois tem como função principal a atuação na fotossíntese. Também é responsável por ativar enzimas, dentre elas a RNA polimerase, possuindo um papel indireto na síntese de proteínas e na multiplicação celular (Malavolta, 1980). Tem, ainda, atuação fundamental na elongação celular (Malavolta et al., 1997), sendo que sua deficiência pode reduzir o crescimento das raízes (Prado, 2008).

As espécies vegetais e os genótipos dentro de cada espécie diferem muito em sua tolerância ao excesso de
Mn (Foy et al., 1988) ou em susceptibilidade a sua deficiência (Graham, 1988), no solo e noutros substratos.

Os sintomas de deficiência e toxicidade de Mn foram constatados em várias culturas e em diversas regiões agrícolas (Abreu et al., 1996). Em solos ácidos é a toxicidade do manganês que causa limitação de produção (Rengel, 2000). Em muitas espécies, os sintomas de toxicidade de manganês são caracterizados por pontuações marrons em folhas maduras (Prado, 2008), que contêm manganês oxidado, mas a coloração amarronzada é devida aos polifenóis oxidados (Wissemeier \& Horst, 1992). Por sua função de ativador enzimático ligado à síntese de clorofila, a deficiência de Mn, além das manchas marrons, também motiva sua distribuição irregular e a deficiência de auxina e de ferro (Souza et al., 1985).

No campo, a desordem nutricional por manganês pode ocorrer em solos de reação ácida, implicando alta concentração do elemento no solo, e induzir sua toxicidade na forrageira. Por outro lado, a aplicação de calcário de forma inadequada, seja com altas doses, ou incorporado superficialmente, poderá aumentar o valor $\mathrm{pH}$ do solo e diminuir a concentração de manganês, induzindo deficiência do nutriente no capim.

Os trabalhos em que se avaliaram os efeitos da aplicação de manganês são poucos. Diante deste contexto, neste trabalho objetivou-se avaliar os efeitos da aplicação de manganês ao solo, no crescimento, na nutrição e na produção de massa de forragem de plantas de Brachiaria brizantha (cv. MG4), em condições de casa de vegetação.

\section{MATERIAL E MÉTODOS}

O experimento foi implantado em casa de vegetação da FCAV/UNESP - Campus de Jaboticabal, com a Brachiaria brizantha Stapf. cv. 'MG4'.

O solo utilizado foi classificado como Latossolo Vermelho distrófico, textura média (EMBRAPA, 2006) e, tinha as seguintes características: $\mathrm{pH}=4,8 ;$ M.O. $=4 \mathrm{~g} \mathrm{dm}^{-}$ ${ }^{3} ; \mathrm{P}=17 \mathrm{mg} \mathrm{dm}^{-3} ; \mathrm{K}=0,2 \mathrm{mmol}_{\mathrm{c}} \mathrm{dm}^{-3} ; \mathrm{Ca}=8 \mathrm{mmol}_{\mathrm{c}} \mathrm{dm}^{-3}$; $\mathrm{Mg}=4 \mathrm{mmol}_{\mathrm{c}} \mathrm{dm}^{-3} ;(\mathrm{H}+\mathrm{Al})=18 \mathrm{mmol}_{\mathrm{c}} \mathrm{dm}^{-3} ;$ Capacidade de 
Troca Catiônica $(\mathrm{CTC})=30,2 \mathrm{mmol}_{\mathrm{c}} \mathrm{dm}^{-3}$; Grau de saturação de bases $(\mathrm{V})=40 \% ; \mathrm{B}=0,21 \mathrm{mg} \mathrm{dm}^{-3} ; \mathrm{Cu}=0,1 \mathrm{mg} \mathrm{dm}^{-}$ 3; $\mathrm{Fe}=1,0 \mathrm{mg} \mathrm{dm}^{-3} ; \mathrm{Mn}=0,6 \mathrm{mg} \mathrm{dm}^{-3} ; \mathrm{Zn}=0,1 \mathrm{mg} \mathrm{dm}^{-3}$. Salienta-se que o teor de Mn no solo é considerado baixo segundo Raij et al. (1997).

Realizou-se a aplicação de calcário $(\mathrm{CaO}=58,5 \% ; \mathrm{MgO}$ $=9 \%$; Poder de Neutralização $(\mathrm{PN})=127 \%$; Poder Relativo de Neutralização Total $($ PRNT $)=99,4 \%$ ), objetivando elevar a saturação por bases a $60 \%$, seguindo indicações para forrageiras do grupo II, segundo Werner et al. (1997).

Após o período de incubação do solo (30 dias), foi realizada a adubação básica, aplicando-se $200 \mathrm{mg} \mathrm{dm}^{-3} \mathrm{de}$ $\mathrm{K}$ (KCl p.a.) (Bonfim et al., 2004), 1,5 $\mathrm{mg} \mathrm{dm}^{-3} \mathrm{de} \mathrm{Cu}$ $\left(\mathrm{CuSO}_{4} .5 \mathrm{H}_{2} \mathrm{O}\right), 0,8 \mathrm{mg} \mathrm{dm}^{-3} \mathrm{de} \mathrm{B}\left(\mathrm{H}_{3} \mathrm{BO}_{3}\right)$ e $0,15 \mathrm{mg} \mathrm{dm}^{-3} \mathrm{de}$ $\mathrm{Mo}\left(\mathrm{NaMoO}_{4} \cdot 2 \mathrm{H}_{2} \mathrm{O}\right)$ e $4,0 \mathrm{mg} \mathrm{dm}{ }^{-3} \mathrm{de} \mathrm{Fe}\left(\mathrm{Fe}_{2}\left(\mathrm{SO}_{4}\right)_{3} \cdot 4 \mathrm{H}_{2} \mathrm{O}\right)$

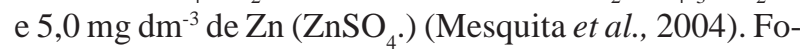
ram ainda aplicados $305 \mathrm{mg}$ de $\mathrm{P} \mathrm{dm}^{-3}$, na forma de superfosfato simples (Mesquita et al., 2004). A dose de nitrogênio foi de $150 \mathrm{mg} \mathrm{de} \mathrm{N} \mathrm{dm}^{-3}$ na forma de ureia,

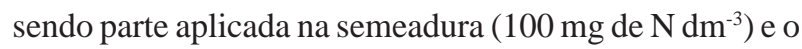
restante aos 30 dias após a semeadura, de acordo com Mesquita et al. (2004).

O delineamento experimental utilizado foi inteiramente casualizado, com cinco tratamentos e quatro repetições. Os tratamentos constituíram-se de doses de manganês: 0 , $15,30,60$ e $120 \mathrm{mg} \mathrm{dm}^{-3} \mathrm{de} \mathrm{Mn}$, na forma de sulfato de manganês (35,5\% de Mn) aplicadas ao solo. A unidade experimental constou de um vaso com capacidade de 4 $\mathrm{dm}^{3}$ preenchido com 3,5 $\mathrm{dm}^{3}$ de amostras de solo.

A semeadura da forrageira foi realizada em bandejas de isopor e, após 10 dias, as mudas foram transplantadas para os vasos, deixando-se quatro plantas por vaso. Nessa época, realizou-se amostragem de solo para análise da concentração de Mn, conforme metodologia descrita por Raij et al. (2001).

A irrigação foi feita pelo método de pesagens dos vasos, mantendo-se a umidade correspondente a $60 \%$ da capacidade de retenção, utilizando-se água deionizada.

As plantas da forrageira foram avaliadas diariamente, quanto à ocorrência de sintomatologia de desordem nutricional e, aos 35 dias após o transplantio, foram realizadas as avaliações referentes à altura das plantas (do colo da planta até a última folha com bainha visível), à área foliar (medida com o aparelho LI-3100 Area Meter) e ao número de folhas e número de perfilhos. Na sequência, as plantas foram cortadas rente ao solo e a massa de forragem obtida foi lavada em água corrente, em solução de detergente neutro $1 \mathrm{~mL} \mathrm{~L}^{-1}$, em água deionizada, em solução de $\mathrm{HCl}$ 0,1 mol $\mathrm{L}^{-1}$, novamente em água deionizada, e seca em estufa, à temperatura de $65 \mathrm{a} 70^{\circ} \mathrm{C}$. A lavagem empregada foi utilizada para descontaminar a amostra, evitando contaminação com solo, que poderia induzir a erros na análise química a ser realizada. Determinou-se a produção da massa de forragem, considerando-se a parte aérea das plantas contidas nos vasos, utilizando-se balança semianalítica. Aos 30 dias após o primeiro corte, foi realizado o segundo corte, seguindo-se os mesmos procedimentos descritos anteriormente. No tecido vegetal, extraiu-se o Mn, de acordo com Bataglia et al. (1983), e determinou-se seu teor por espectrometria de absorção atômica; com os dados da matéria seca, calculou-se o acúmulo do nutriente na parte aérea da forrageira para os dois cortes.

Os dados coletados para cada variável foram submetidos à análise de variância, a 5\% de significância, e os subsequentes resultados, submetidos à análise de regressão, por meio do programa estatístico SAS (2005).

\section{RESULTADOS E DISCUSSÃO}

As doses de manganês aplicadas aumentaram a concentração desse micronutriente no solo de forma linear (Figura 1). Embora tenha ocorrido variação no teor de Mn no solo, mesmo nos tratamentos que não receberam aplicação deste nutriente, ela não foi relevante, pois os teores ainda são classificados como baixos. Possivelmente, esse aumento pode ter recebido contribuição dos fertilizantes aplicados (como o superfosfato simples), que podem apresentar resíduos de $\mathrm{Mn}$.

Para a dose de $120 \mathrm{mg} \mathrm{dm}^{-3}$, o valor observado chegou a $14 \mathrm{mg} \mathrm{dm}^{-3}$, o que, segundo Raij et al. (1997) é considerado alto. Entretanto, mesmo nas maiores doses, houve baixa eficiência para elevação dos teores, provavelmente pela aplicação inicial de calcário, visando a elevar o $\mathrm{V}$ a $60 \%$ e pela alta adsorção de Mn ao solo.

O incremento da concentração de manganês no solo, em função da aplicação deste micronutriente, refletiu-se no teor (Figura 2a) e no acúmulo (Figura 2b) na parte aérea, atingindo, no primeiro e no segundo cortes, teores de 420 e $1218 \mathrm{mg} \mathrm{kg}^{-1}$, e acúmulos de 4,3 e 5,7 mg de Mn por planta, respectivamente. Esses teores estão muito acima da faixa considerada adequada (40 e $250 \mathrm{mg} \mathrm{kg}^{-1}$ ), segun-

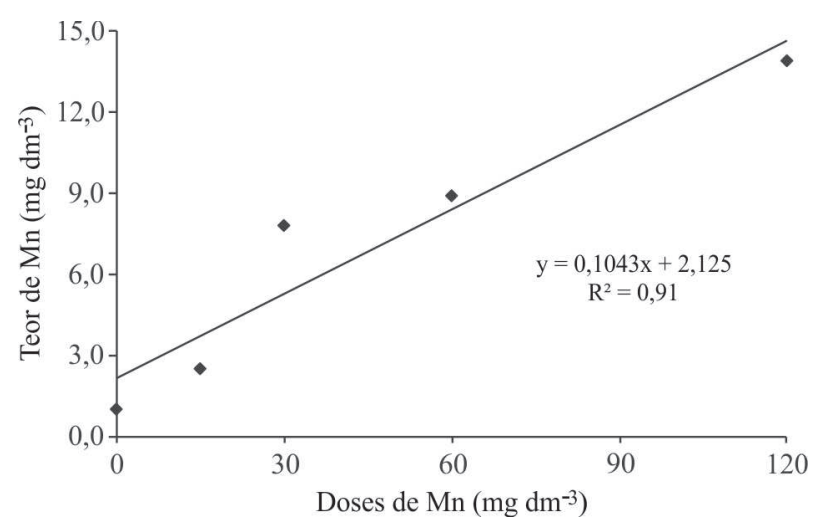

Figura 1. Teor de Mn no solo em função da aplicação de manganês.

Rev. Ceres, Viçosa, v. 58, n.6, p. 811-816, nov/dez, 2011 
do Werner et al. (1997), para gramíneas forrageiras do grupo II, apesar de não terem sido observados sintomas característicos de desordens nutricionais na forrageira, assim como no presente trabalho. Esse fato ocorre por causa da ampla faixa que seria considerada adequada (de 40 até $250 \mathrm{mg} \mathrm{kg}^{-1}$ ), sendo indicada para um grupo muito grande de espécies vegetais, que estariam no grupo II, e associada com tecido vegetal jovem (brotação nova e folhas verdes). Não existem informações de teores adequa- dos de Mn, especificamente para o cultivar utilizado no trabalho. Assim, as diferenças de genótipo e de tecido vegetal (pois foi coletada a parte aérea das plantas), explicam as possíveis diferenças entre os teores de Mn obtidos e os descritos na literatura.

Ferreira et al. (2009) estudaram a resposta de cultivares de arroz de terras altas à fertilização com $\mathrm{Mn}$, em Latossolo Amarelo, em vaso e em casa de vegetação, tendo verificado que nenhum cultivar apresentou sintomas
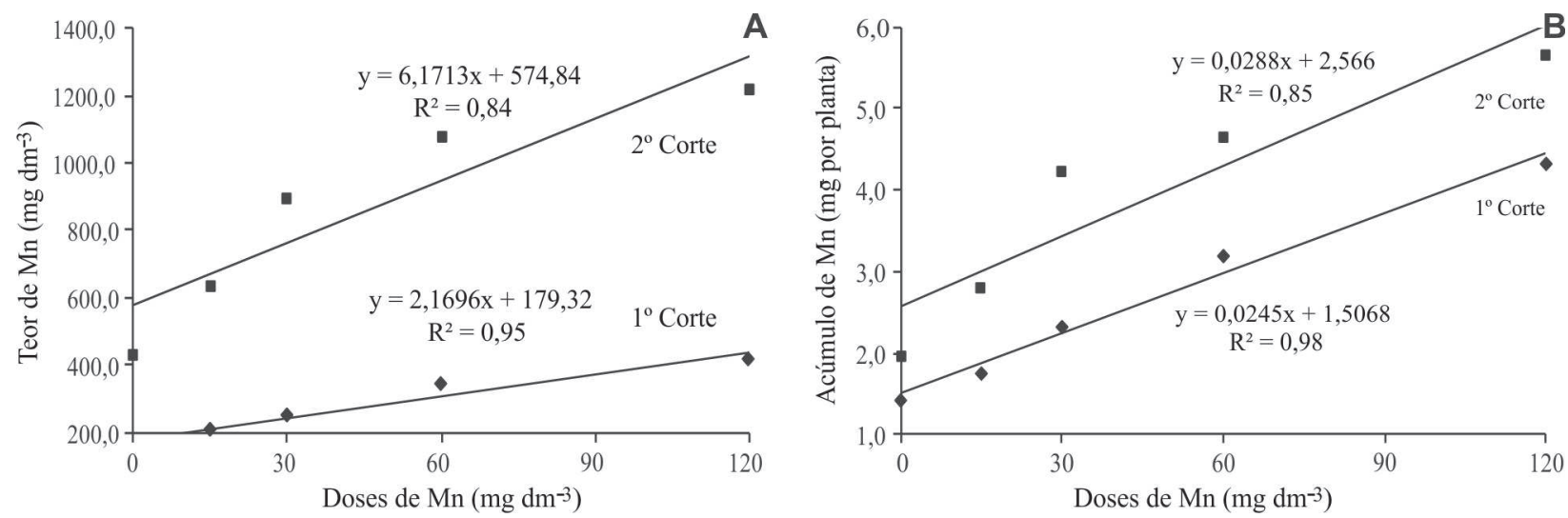

Figura 2. Teor (a) e acúmulo (b) de Mn na parte aérea das plantas de Brachiaria brizantha cv. MG4, em dois cortes, em função da aplicação de manganês.
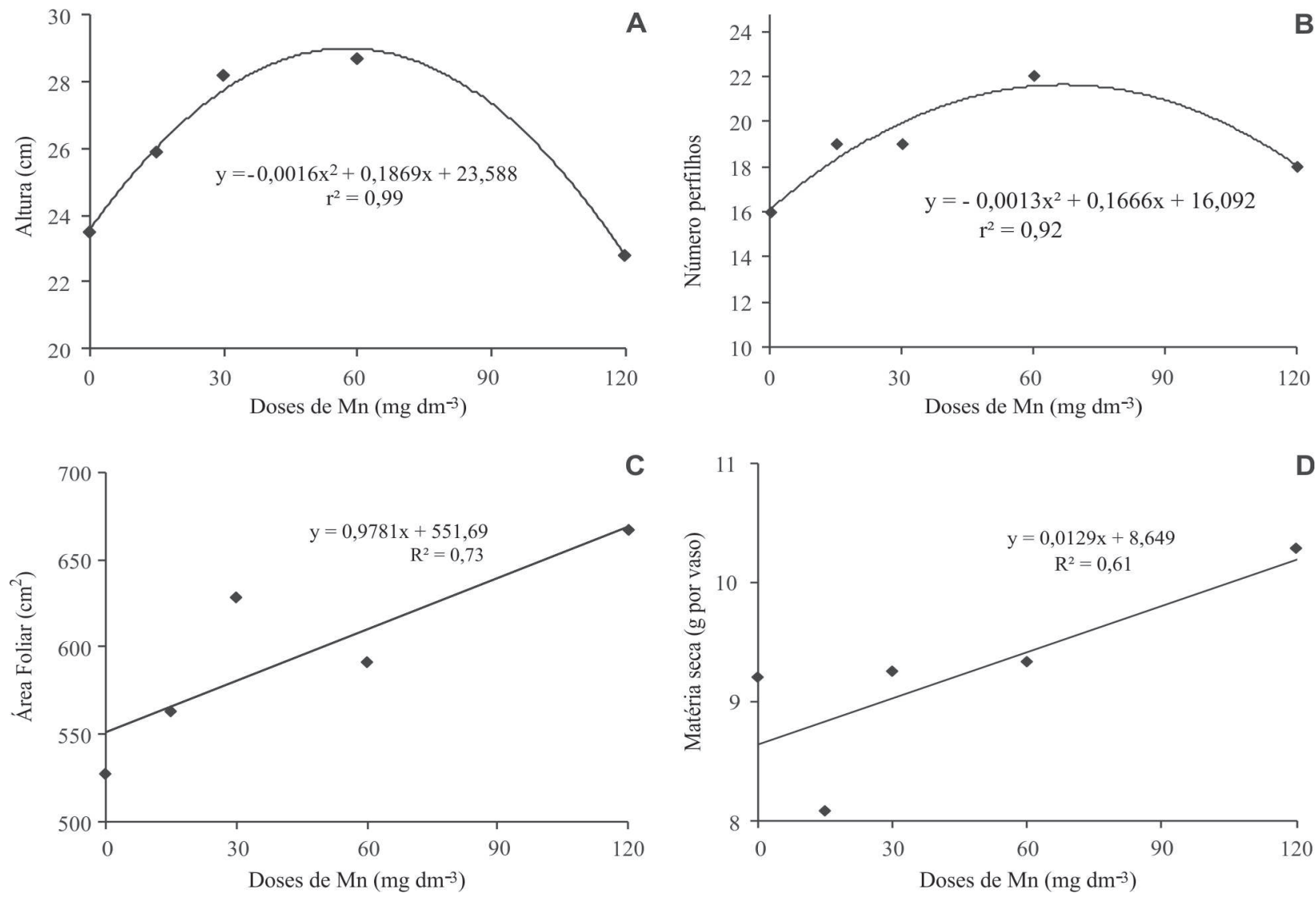

Figura 3. Altura de plantas (a), número de perfilhos (b), área foliar (c) e matéria seca (d) das plantas de Brachiaria brizantha cv. MG4 em função da aplicação de manganês, no primeiro corte.

Rev. Ceres, Viçosa, v. 58, n.6, p. 811-816, nov/dez, 2011 
de toxicidade, mesmo quando a parte aérea das plantas apresentava teores elevados de Mn (1092 $\left.\mathrm{mg} \mathrm{kg}^{-1}\right)$.

A concentração do manganês que provoca toxicidade varia amplamente, entre as espécies e variedades de plantas, possivelmente porque os mecanismos de tolerância ao Mn fitotóxico envolvem diferentes vias bioquímicas, específicas para cada genótipo (El-Jaqual \& Cox, 1998), ou, mesmo, translocação do elemento a outros órgãos (Vose \& Randall, 1962). Há também um mecanismo de tolerância dos tecidos internos, pois elevados teores de manganês são permitidos dentro das folhas ou raízes, sem nenhum efeito tóxico aparente (Ross \& Kaye, 1994).

A aplicação de manganês influenciou as variáveis de crescimento apenas no primeiro corte e, o número de folhas, em ambos os cortes. No primeiro corte, observou-se um incremento na altura e no número de perfilhos da forrageira, com ajuste quadrático, sendo que a dose que proporcionou ponto de máximo foi $58,4 \mathrm{mg} \mathrm{dm}^{-3}$ (Figura 3a) e de $64,1 \mathrm{mg} \mathrm{dm}^{-3}$ (Figura 3b), respectivamente, enquanto a área foliar da forrageira, no primeiro corte, apresentou comportamento linear crescente (Figura 3c).

Esse aumento na matéria seca da forrageira, no primeiro corte, em função da aplicação de manganês (Figura $3 \mathrm{~d}$ ), seria reflexo dos efeitos desse micronutriente nas variáveis de crescimento, vistos anteriormente, e pode ser devido ao efeito na nutrição da planta, atuando como ativador enzimático e sendo componente da dismutase de superóxido, que protege os tecidos dos radicais livres tóxicos (Marschner, 1995). Por sua deficiência, ocorre inibição da síntese de lipídios (Malavolta et al., 1997) e diminuição do fluxo de carboidratos para as raízes, decrescendo assim a produção de massa de forragem.

Cabe salientar que o uso da maior dose do micronutriente proporcionou alto teor do Mn na planta, em ambos os cortes, e não resultou em prejuízo na produção de massa de forragem. Resultados semelhantes foram constatados por Einloft et al (1999), em estudos com diferentes espécies vegetais, em substratos ricos em manganês, e puderam observar que, no grupo das gramíneas, a $B$. brizantha apresentou alto teor de $\mathrm{Mn}$, sem, entretanto, ocorrer redução da matéria seca da parte aérea nem das raízes. Também não mostraram sintomas de toxicidade nas folhas, devidos a este micronutriente.

\section{CONCLUSÕES}

As doses de manganês aplicadas aumentaram a concentração de Mn no solo e nas plantas e a produção de massa de forragem apenas no primeiro corte da forrageira.

A Brachiaria brizantha cv. 'MG4' apresenta alta tolerância ao manganês, atingindo elevados teores do micronutriente na parte aérea, no primeiro e segundo corte, sem se apresentarem sintomas de toxicidade.

\section{REFERÊNCIAS}

Abreu CA, Van Raij B \& Tanaka, RT (1996) Fontes de manganês para a soja e seus efeitos na análise do solo. Revista Brasileira de Ciência do Solo, 20:91-97.

Bataglia OC, Furlani AMC, Teixeira JPF, Furlani PR \& Gallo JR (1983) Métodos de análises química de plantas. Campinas: Instituto Agronômico. 48 p. (Boletim Técnico, 78).

Bonfim SEM, Freire FJ, Santos MVF, Silva TJA \& Freire, MBGS (2004) Soil and plant phosphorus critical levels for Brachiaria brizantha related to physical and chemical characteristics of soils in the State of Pernambuco, Brazil. Revista Brasileira de Ciência do Solo, 28: 281-288.

Braz SP, Nascimento Jr D, Cantarutti RB, Adair JR, Martins CE, Fonseca DM, Barbosa RA (2002) Aspectos quantitativos do processo de reciclagem de nutrientes pelas fezes de bovinos sob pastejo em pastagem de Brachiaria decumbens na Zona da Mata de Minas Gerais. Revista Brasileira de Zootecnia, 31: 858865 .

El-Jaqual T \& Cox DA (1998) Manganese toxicity in plants. Journal of Plant Nutrition, 21:353-386.

EMBRAPA (2006) Centro Nacional e Pesquisa em Solos. Sistema Brasileiro de Classificação de Solos. Brasilia: Embrapa-SPI; Rio de Janeiro: Embrapa-Solos. 306p.

Einloft R, Ruiz HA, Griffith JJ, Pereira PRG \& Abrahão WAP (1999) Crescimento de gramíneas e leguminosas em substrato rico em manganês proveniente de área de empréstimo. Revista Árvore, 23: 203-212.

Ferreira EVO, Carvalho JG, Faria Júnior LA, Bastos ARR \& Pinho PG (2009) Manganês na nutrição mineral de cultivares de arroz de terras altas. Pesquisa Agropecuária Tropical, 39: 151-157.

Foy CD, Scott BJ \& Fisher JA (1988) Genetics and breeding of plant of manganese toxicity. In: Graham RD, Hannam RJ \& Uren NC (Eds.) Manganese in soils and plants. Dordrecht, Kluwer Academic Publishers, p.293-307.

Graham, RD (1988) Genotypic differences in tolerance to manganese deficiency. In: Graham RD, Hannam RJ \& Uren NC (Eds.) Manganese in soils and plants. Dordrecht, Kluwer Academic Publishers, p.261-276.

Kissmann KG (1997). Plantas infestantes e nocivas. $2^{a}$ ed. São Paulo, Basf Brasileira. 825 p.

Malavolta E (1980) Elementos de nutrição mineral das plantas. São Paulo, Ceres. 251p.

Malavolta E, Vitti GC \& Oliveira SA de (1997) Avaliação do estado nutricional das plantas: princípios e aplicações. 2. ed. Piracicaba, Potafos. 319p.

Marschner H (1995) Mineral nutrition of higher plants. London, Academic Press. 889p.

Mesquita EE, Pinto JC, Furtini Neto AE, Santos IPA \& Tavares VB (2004) Critical phosphorus concentrations in three soils for the establishment of mombaça grass, marandu grass and andropogon grass. Revista Brasileira de Zootecnia., 33: 290301.

McDowell LR \& Valle G (2000) Major minerals in forages. In: Givens DJ, Owen E, Axford RFE \& Omed HM (Eds). Forage evaluation in ruminant nutrition. New York, Cabi publishing. p.373-397.

Monteiro FA, Ramos AKB, Carvalho DD, Abreu JBR, Daiub JAS, Silva JEP, Natale W (1995) Cultivo de Brachiaria brizantha Stapf. cv. Marandu em solução nutritiva com omissões de macronutrientes. Scientia Agricola, 52: 135-141.

-Rev. Ceres, Viçosa, v. 58, n.6, p. 811-816, nov/dez, 2011 
Oliveira PPA, Marchesin W, Luz PHC, Herling VR (2007) Guia de identificação de deficiências nutricionais em Brachiaria brizantha cv. marandu. Comunicado técnico Embrapa, n.76, $38 \mathrm{p}$

Pereira GD, Bertoni JC, Carvalho JG \& Morais AR (2001) Doses e modos de adubação com manganês e seus efeitos na produção da cultura do arroz. Revista Brasileira de Ciência do Solo, 25: 625-633.

Prado RM (2008) Manual de nutrição de plantas forrageiras. Jaboticabal, FUNEP. 413p.

Raij B van, Cantarella H, Quagio JA \& Furlani AMC (1997) Recomendações de adubação e calagem para o estado de São Paulo $2^{\mathrm{a}}$ ed. Campinas, IAC. 285p. (Boletim Técnico, 100).

Raij B van, Andrade JC, Cantarella H \& Quaggio JA. (Ed.) (2001) Análise química para avaliação da fertilidade do solo. Campinas, IAC. 285 p.

Rengel Z (2000) Uptake and transport of manganese in plants. In: Sigel A \& Sigel H (Eds.) Metal ions in biological systems. New York, Marcel Dekker. p.57-87.

Ross SM \& Kaye KJ (1994) The meaning of metal toxicity in soil plant systems. In: Ross SM (Ed.) The meaning of metal toxicity in soil-plant systems. Chichester, John Wiley \& Sons. p.27-61.

Sanzonowicz C (1995) Deficiência de manganês em solos dos cerrados. In: Yamada T (Ed.). Informações agronômicas. Piracicaba, Potafos. p.7 (Boletim, 71).
SAS Institute (2005) User's guide, version 9.0. Cary: SAS Institute.

Soder KJ \& Stout WL (2003) Effect of soil and fertilization level on mineral concentration of pasture: potencial relationships to ruminant performance and health. Jounal of Animal Science, 81: $1603-1610$.

Souza DMG \& Carvalho LJCB (1985) Nutrição mineral de plantas. In: Goedert WJ (Ed.). Solos dos cerrados: tecnologias e estratégias de manejo. Planaltina, EMBRAPA/Cerrados. p.7598

Tanaka RT, Mascarenhas HAA \& Bulisani EA (1993) Manganese deficiency in soybeans induced by excess lime. In: Armstrong D L (Ed.). Better Crops International. Norcross, Potash \& Phosphate Institute. p.7. Vose PB \& Randall PJ (1962) Resistance to aluminum and manganese toxicities in plants related to variety and cation exchange capacity. Nature, 196: 85-86.

Werner JC, Paulino JC, Cantarella H, Quaggio JA \& Andrade NO (1997) Forrageiras. In: Raij B Van, Cantarella H, Quaggio JA \& Furlani AMC. (Eds.). Recomendações de adubação e calagem para o estado de São Paulo. $2^{\mathrm{a}}$ ed. Campinas, IAC. p.263-273 (Boletim Técnico, 100).

Wissemeier AH \& Horst WJ (1992) Effect of light intensity on manganese toxicity symptoms and callose formation in cowpea (Vigna unguiculata (L.) Walp.). Plant and Soil, 143: 299-309. 